\title{
Assessment of the environmental situation in Krasnoyarsk using remote sensing data
}

\author{
Konstantin V. Krasnoshchekov, Oleg E. Yakubailik ${ }^{2}$ \\ ${ }^{1}$ Federal Research Center Krasnoyarsk Science Center SB RAS, Krasnoyarsk, Russia \\ ${ }^{2}$ Institute of Computational Modelling SB RAS, Krasnoyarsk, Russia
}

\begin{abstract}
The data on ground concentrations of aerosols and small gas components (particulate matter $\mathrm{PM}_{2.5}$ and sulfur dioxide $\mathrm{NO}_{2}$ ) were compared with remote sensing data obtained over the territory of Krasnoyarsk from June to August 2020. We use the air monitoring system of the Krasnoyarsk Scientific Center of the Siberian Branch of the Russian Academy of Sciences (KSC SB RAS) to determine the concentration of $\mathrm{PM}_{2.5} . \mathrm{NO}_{2}$ concentrations were taken according to the data of the State departmental information and analytical system of the Ministry of Ecology of the region. It is shown that the remote sensing data of the MODIS MAIAC algorithm with a spatial resolution of $1 \mathrm{~km}$ can be used to determine the concentration of $\mathrm{PM}_{2.5}$ as an addition to the data obtained by the ground-based air monitoring system of the KSC SB RAS. The MAIAC data were calculated using two different models and are given to the measurement system used in the KSC SB RAS monitoring network. A high coefficient of determination between satellite and ground monitoring data was obtained. Determination coefficients were also obtained for $\mathrm{NO}_{2}$, showing how applicable the remote sensing data are for assessing the environmental situation in Krasnoyarsk.
\end{abstract}

\section{Keywords}

Environmental monitoring, MODIS MAIAC, $\mathrm{PM}_{25}$, aerosol, AOD, Krasnoyarsk.

\section{Introduction}

The issue of air quality assessment is particularly acute in large industrial and developing cities. The low quality of atmospheric air affects the health of the population and the state of the environment in general. Air consists of a mixture of different gases. Air quality is determined by a combination of various physical, chemical, and biological properties. One of the main parameters for assessing atmospheric air quality is the concentration of small gas components (SGC). The small gas components of the atmosphere include methane, carbon monoxide, nitrogen dioxide, etc. The concentration of SGC has a significant impact on the absorption of optical radiation, and increased concentrations of SGC harm the population's health. In addition to SGC, aerosols or particulate matter $(\mathrm{PM})$ are present in the air. Particulate matter of natural or anthropogenic origin significantly impacts the climate and environment and, like SGC, harms human health [1]. Various epidemiological studies link increased PM concentrations with an increase in the number of deaths and an increase in respiratory diseases [2]. The results of toxicological studies indicate

SDM-2021: All-Russian conference, August 24-27, 2021, Novosibirsk, Russia

@krasko@icm.krasn.ru (K.V. Krasnoshchekov); oleg@icm.krasn.ru (O.E. Yakubailik)

(D) 0000-0002-2668-4776 (O.E. Yakubailik)

(c) (1) $\odot 2021$ Copyright for this paper by its authors. Use permitted under Creative Commons License Attribution 4.0 International (CC BY 4.0).

CEUR Workshop Proceedings (CEUR-WS.org) 
the possibility of particulate matter with a size of 10 microns $\left(\mathrm{PM}_{10}\right)$ or less entering the blood through the lungs, thereby harming health [3].

After twenty years of epidemiological studies, scientists have found a significant correlation between fine pollutants and respiratory morbidity [4]. It was shown in [5, 6] that an increased PM concentration in the air could directly lead to an increase in morbidity and mortality of the population. According to the results of work [7] in the countries of the European Union, the presence of elevated $\mathrm{PM}_{2.5}$ values in the air (PM with diameters less than 2.5 microns) reduced the average life expectancy by 8.6 months. After a study of 29 European countries, the authors of [8] found that respiratory mortality increases by $0.58 \%$ for every $10 \mathrm{mg} / \mathrm{m}^{3}$ increase in $\mathrm{PM}_{10}$. It was reported in $[9,10]$ that the prevalence of respiratory diseases increased by $2.07 \%$, and the frequency of hospitalizations increased by $8 \%$ when the daily norm of $\mathrm{PM}_{2.5}$ increased by $10 \mathrm{mg} / \mathrm{m}^{3}$. Therefore, the assessment of air quality, especially from the point of view of $\mathrm{PM}_{10}$ and $\mathrm{PM}_{2.5}$, is an urgent problem at the moment.

Krasnoyarsk is an actively developing city. Currently, in the city, monitoring stations using the optical registration method and the weight method are mainly used to determine PM concentration. Ground-based observations from monitoring stations show important spatial and temporal information about the concentration of PM in the atmosphere. Although the network of monitoring stations in the city has dozens of observation posts, point measurements do not provide information about PM's spatial characteristics and distribution of PM in urban areas of interest, nor do they show the influence of the city's atmosphere on the surrounding areas.

The influence of external factors contributing to pollution in the city (the private sector, industrial facilities located outside the city) is also of interest. The time coverage of on-site PM measurements also varies greatly depending on the device's operation period and its functionality. These reasons have led to ongoing efforts to assess PM using satellite remote sensing techniques.

Nitrogen dioxide $\mathrm{NO}_{2}$, like $\mathrm{PM}$, harms the body. The main sources of $\mathrm{NO}_{2}$ are car exhaust gases, CHP emissions, solid waste incineration, gas combustion. If a small concentration of nitrogen dioxide enters the respiratory organs, a person experiences respiratory disorders, coughing, an increase in concentration can lead to oxygen starvation and other negative consequences. Nitrogen dioxide also negatively affects the environment, increasing the soil's acidity, adversely affecting vegetation, and plays an important role in the formation of urban smog.

\section{Data and measurements}

\subsection{Study area}

The city of Krasnoyarsk is the regional center of the Krasnoyarsk Territory, with a population of more than 1 million people. It is actively developing and has an area of about $350 \mathrm{~km}^{2}$. The coordinates of the city center are $56^{\circ} 00^{\prime}$ north latitude and $92^{\circ} 52^{\prime}$ east longitude. The city and the surrounding territories have a unique relief. From the south and west of the city, there are forests and hilly terrain. From the north and east, the terrain is mostly flat. The Yenisei River, which does not freeze in winter due to the nearby Krasnoyarsk hydroelectric power station, divides 
the city approximately in half. Like all major cities, Krasnoyarsk is subject to a negative impact on the environmental situation. Motor transport, the private sector, thermal power plants, large enterprises of the metallurgical, machine-building, and chemical industries contribute many emissions into the atmosphere and negatively affect the quality of the surrounding air. The concentration of $\mathrm{PM}_{2.5}$ in Krasnoyarsk is $64 \%$ higher than the average in Russia [11].

\subsection{Satellite data}

The aerosol optical depth (AOD) parameter is usually used [12]. AOD is an integrated atmospheric scattering of radiation by aerosols in a vertical column of the atmosphere. This parameter is proportional to the number of particles in the air and depends on their mass concentration.

In our work, we used the data of the MAIAC product. This algorithm was developed for processing MODIS data. MAIAC extracts aerosol parameters above the ground with a resolution of $1 \mathrm{~km}$ [13]. The MCD19A2 product (MAIAC) contains data from the MODIS spectrophotometer installed on the Terra and Aqua satellites. This product was published on May 30, 2018, containing AOD data from February 1, 2000. Aerosol parameters include the optical depth at a wavelength from 0.47 to 0.67 microns and the type of aerosol, including models of background, smoke, and dust.

The increased accuracy of MAIAC results from using the explicit surface characterization method instead of the empirical approach to surface parameterization, which is used in the MOD04 and MYD04 algorithms. In addition, MAIAC includes a cloud mask algorithm based on spatial-temporal analysis, which complements traditional methods of detecting clouds at the pixel level [13]. MAIAC provides a uniform grid resolution of $1 \mathrm{~km}$ in the selected projection, regardless of the scanning angle.

To determine how much AOD correlates with ground-based PM measurements, numerous linear, chemical [14], transport [15], and neural [16] models have been developed. However, the particle size distribution, composition, air humidity, and wind speed significantly reduce the AOD-PM correlation [17]. The correlation between the measurements of the total AOD column and the near-surface $\mathrm{PM}_{25}$ and these variables was investigated [18]. These studies have shown a wide range of correlations between $\mathrm{AOD}$ and $\mathrm{PM}_{25}$ mass.

The method of obtaining data is based on the reflection of various wavelengths from the Earth's surface and the registration of reflected radiation on the device's sensor. Because of this, incorrect values are obtained on a highly reflective surface (snow, water, cloud cover). Therefore, data on the territory of Krasnoyarsk becomes available after the snow cover disappears and before it appears.

We used the OMNO2d product as satellite data on nitrogen dioxide. This product provides data on $\mathrm{NO}_{2}$ in a vertical column of the atmosphere with a spatial resolution of $0.25 \times 0.25$ degrees. The OMNO2d product contains daily $\mathrm{NO}_{2}$ values for the entire territory of the Earth from October 1, 2004, to the present [19]. This product is available throughout the year over Krasnoyarsk, except if the cloud cover exceeds $30 \%$. This product has a rough spatial resolution, which is not suitable for assessing the environmental situation in the city at the district level. However, this spatial resolution will allow us to assess the impact of the city on the nearest territories and the contribution of external factors to the concentration of $\mathrm{NO}_{2}$ in the city. 


\subsection{Ground area}

The data on $\mathrm{PM}_{25}$ of the air monitoring system of the Krasnoyarsk Scientific Center, consisting of 26 monitoring posts, were used in work. A certified CityAir air monitoring station developed by a group of companies from the Novosibirsk Technopark and the Skolkovo Innovation Center is installed at each monitoring post. These stations provide information about the state of the surrounding air, its temperature, pressure, and humidity. Additionally, an optical sensor is installed inside the station to measure the concentrations of $\mathrm{PM}_{25}$ and $\mathrm{PM}_{10}$.

Data on $\mathrm{NO}_{2}$ were obtained from the State regional environmental departmental information and analytical data system of the Krasnoyarsk Territory. There are 7 automated observation posts (AOP) installed on the territory of Krasnoyarsk, providing information on the concentrations of carbon monoxide, sulfur dioxide, nitrogen dioxide, hydrogen sulfide, and other pollutants. For our study, we used data from two AOPs since data from other AOP had gaps in the study period. In Figure 1, a red circle is circled the monitoring stations used to determine the concentrations of $\mathrm{PM}_{25}$ and $\mathrm{NO}_{2}$.

\subsection{Meteorological observations}

To assess the compliance of the satellite sensing data with the ground monitoring data, the satellite sensing data were adjusted according to meteorological parameters. We used data on temperature, humidity, and atmospheric air pressure. All these parameters were obtained using a network of monitoring posts of the KSC SB RAS. In addition to the parameters given above, the planetary boundary layer height (PBLH) obtained from the atmospheric model of the Global Forecasting System (GFS) was used.

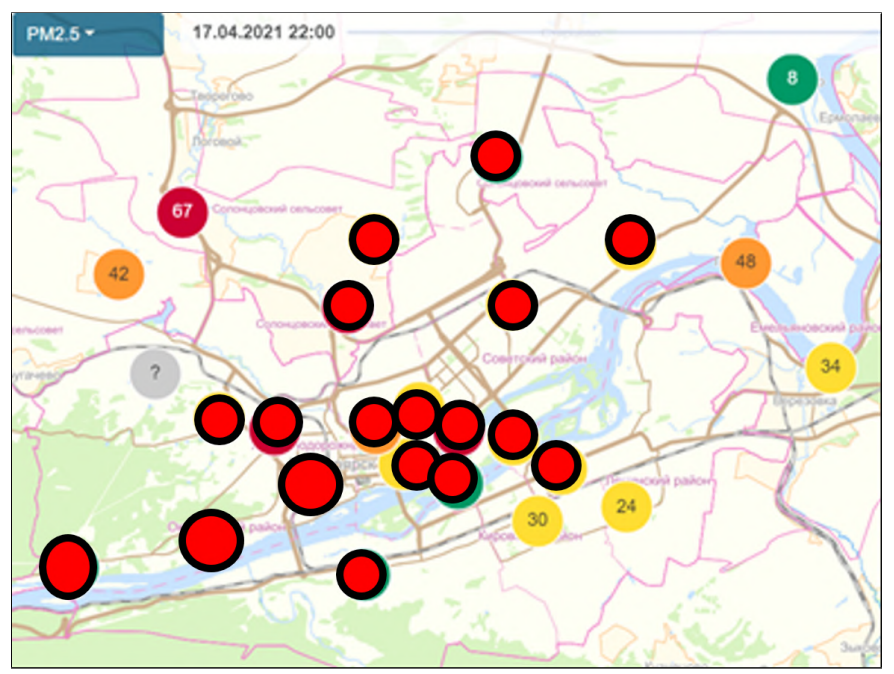

Figure 1: Location of automated observation posts in Krasnoyarsk. 


\section{5. $\mathbf{P M}_{2.5}$ estimation based on satellite data}

To assess the extent to which satellite monitoring data can be used to analyze the environmental situation in the city according to the $\mathrm{PM}_{25}$ parameter, we calculated the correlation coefficient between the $\mathrm{PM}_{25}$ data obtained from ground-based observations and the data on the AOD parameter obtained from satellite monitoring data. Since the AOD data is available only in the absence of snow cover, the period from June to August 2019 and 2020 was taken, a total of 184 days. However, the AOD data is also limited by the presence of cloud cover. As a result, the final number of days used in the calculations was 80. For comparison, the AOD data located above the ground monitoring station was taken, then they were averaged, getting an average value over the city. The ground monitoring data was taken as the $\mathrm{PM}_{25}$ concentration value measured for 12 hours of the day. The data between the posts was averaged, obtaining the average $\mathrm{PM}_{2.5}$ value in the city.

To compare the AOD and $\mathrm{PM}_{25}$ data, the AOD data were recalculated to $\mathrm{PM}_{25}$ units of measurement $\left(\mathrm{mg} / \mathrm{m}^{3}\right)$. We used two models.

The first model has a linear form, as shown in formula (1)

$$
\mathrm{PM}_{\text {calc }}=a \cdot \mathrm{AOD}+B
$$

where $\mathrm{PM}_{\text {calc }}$ is the calculated $\mathrm{PM}$ values in $\mathrm{mg} / \mathrm{m}^{3}, a$ and $B$ are linear regression coefficients and are equal to $7.2 \cdot 10^{-3}$ and $5.3 \cdot 10^{-3}$, respectively. The result obtained using this formula is shown in Figure 2.

The next model considered has the form shown in formula (2). It includes meteorological parameters and takes into account aerosol characteristics. This formula is widely used for comparing AOD and PM data:

$$
\mathrm{PM}_{\text {calc }}=\frac{\mathrm{AOD}}{\mathrm{PBLH}} /\left(K \cdot\left[\frac{1-\mathrm{RH}}{1-\mathrm{RH}_{0}}\right]^{-\gamma}\right)
$$

To obtain the calculated values according to the formula (2), it is necessary to take into account, in addition to the AOD values, such parameters as PBLH - the height of the boundary layer of the atmosphere, $\mathrm{RH}$ - air humidity, $\mathrm{RH}_{0}$ - the average value of air humidity for the selected territory, the variables $\gamma$ and $K$ are aerosol characteristics and are obtained from [11]. The results obtained by formula (2) are shown in Figure 3.

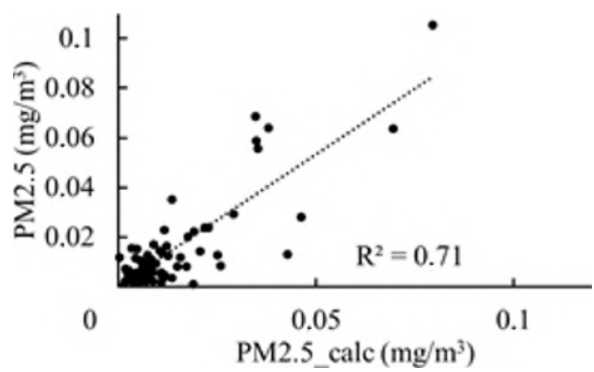

Figure 2: Comparison of ground data ( $y$-axis) and calculated $\mathrm{PM}_{25}$ values obtained from the first model (x-axis). 


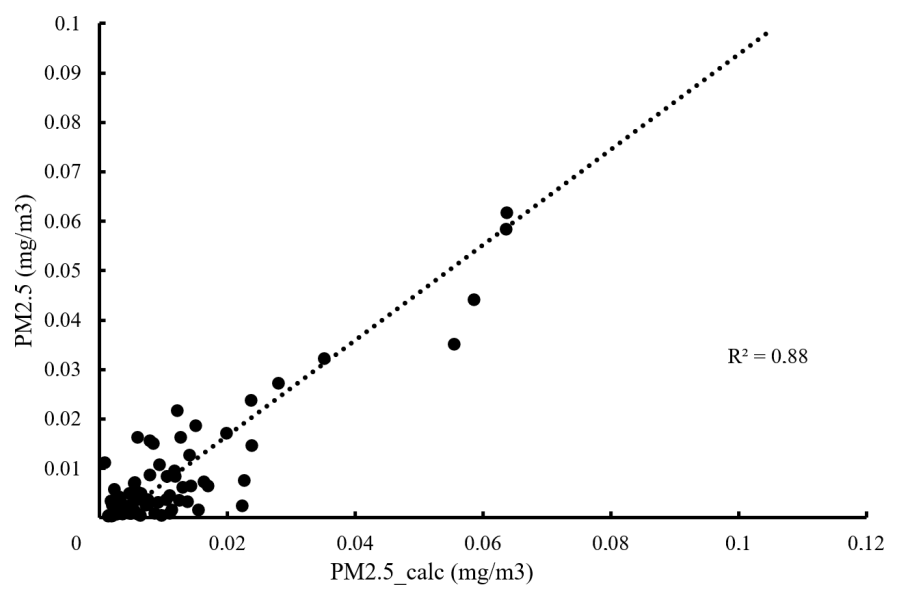

Figure 3: Comparison of ground data (y-axis) and calculated $\mathrm{PM}_{25}$ values obtained from the second model (x-axis).

\section{6. $\mathrm{NO}_{2}$ estimation based on satellite data}

To assess the extent to which satellite monitoring data can be used to assess the environmental situation in the city according to the $\mathrm{NO}_{2}$ parameter, we calculated the correlation coefficient between $\mathrm{NO}_{2}$ data obtained from ground-based observations and $\mathrm{NO}_{2}$ data obtained from satellite monitoring data. Since the data has a spatial resolution of 0.25 degrees, the territory of Krasnoyarsk is covered by two pixels, which were averaged. The time period from June 1 to August 31, 2020, was chosen to compare satellite and ground data. $\mathrm{NO}_{2}$ satellite monitoring data is provided in moles/ $\mathrm{cm} 3$ units in the vertical column of the atmosphere, data from ground monitoring posts are provided in $\mathrm{mg} / \mathrm{m} 3$ units. To calculate the correlation coefficient between

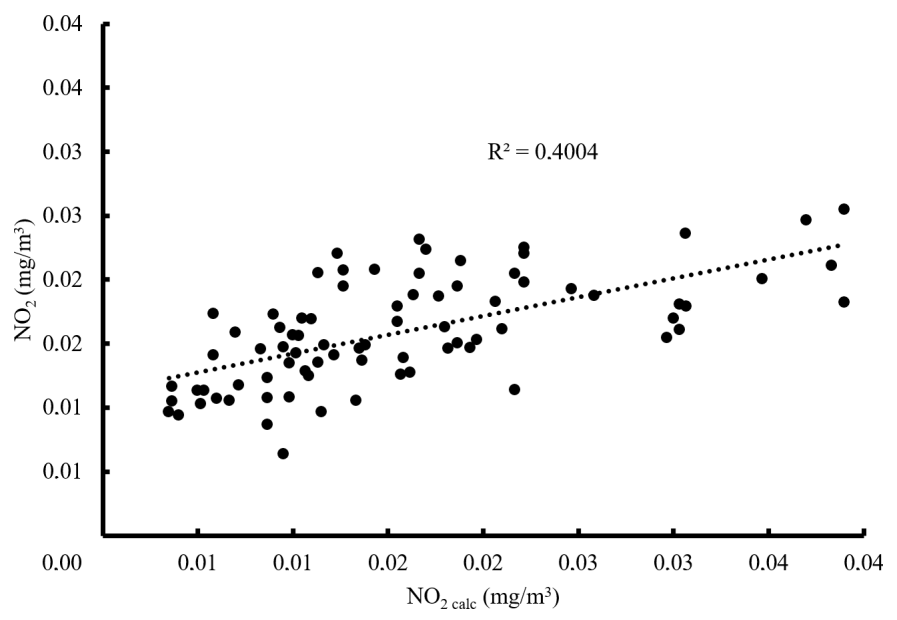

Figure 4: Comparison of $\mathrm{NO}_{2}$ ground data (y-axis) and $\mathrm{NO}_{2}$ values calculated using formula (3) (x-axis). 
the two data series, we converted the satellite monitoring data series using formula (3).

$$
\mathrm{NO}_{2 \text { calc }}=a \cdot \mathrm{NO}_{2 \text { sat }}+b \cdot R+c \cdot T+d \cdot P+e \cdot \mathrm{PBLH}
$$

where $\mathrm{NO}_{2}$ sat is the $\mathrm{NO}_{2}$ data obtained using the OMNO2d product, $R$ is the air humidity, $T$ is the air temperature, $P$ is the air pressure, $\mathrm{PBLH}$ is the height of the atmospheric boundary layer. The results obtained using formula (3) are shown in Figure 4.

\section{Results and discussion}

Satellite AOD measurements, ground-based $\mathrm{PM}_{25}$ data, and meteorological parameters were used to compare the $\mathrm{PM}_{25}$ data. Applying formula (1) for the satellite data series and comparing the calculated data series with ground measurements, we obtain the graph shown in Figure 2.

Satellite monitoring data were converted to the units of ground monitoring stations data and then compared with them. The coefficient of determination between these data sets was calculated $\left(R^{2}=0.71\right)$. Such a high value of the coefficient of determination suggests that the data for PM, calculated using satellite monitoring, have high compliance with the data measured by ground monitoring stations.

The next stage of the work is to obtain the calculated values of $\mathrm{PM}_{\text {calc }}$ using the formula (2). The result is shown in Figure 3.

When adding meteorological parameters and aerosol characteristics of $\mathrm{PM}_{25}$ to the model, it was possible to increase the correlation between the two data series significantly. Therefore, satellite monitoring data can be used in addition to data from ground observation posts to improve the assessment of the environmental situation in Krasnoyarsk. However, the data from the first model can also be used to assess air quality since they have a strong correlation with ground data. Data from the linear model can be used in places where weather parameters are unknown.

To compare the $\mathrm{NO}_{2}$ data, we also used data obtained using satellite measurements and ground measurements at monitoring posts. Weather parameters were also used to increase the correlation between these two data series.

Applying formula (3) to a series of data obtained from satellite measurements and comparing the calculated data series with ground monitoring data, we obtain the graph shown in Figure 4.

The value of the determination coefficient for $\mathrm{NO}_{2}$ is worse than the value for $\mathrm{PM}_{25}$. Most likely, this is due to the coarser spatial resolution of satellite data. However, this accuracy is sufficient for assessing the impact of the urban environmental situation on the surrounding suburban territory; this accuracy is sufficient.

\section{Conclusions}

The joint processing of data from ground-based monitoring networks with remote sensing data will improve the assessment of Krasnoyarsk's environmental situation. It will be possible to obtain data on the spatial distribution of pollution in the city, which will strengthen the understanding of the influence of the city's atmosphere on the surrounding areas and the influence of the surrounding areas on the environmental situation in the city. 
Using satellite monitoring data, it is possible to significantly supplement the data obtained from ground monitoring posts, strengthening the understanding of atmospheric processes occurring in the city and beyond.

\section{References}

[1] Y. Kaufman, D. Tanré, O. Boucher, A satellite view of aerosols in the climate system, Nature (2002) 215-223. doi:10.1038/nature01091.

[2] J. Schwartz, F. Laden, A. Zanobetti, The concentration-response relation between PM(2.5) and daily deaths, Environmental Health Perspectives (2002). doi:10.1289/ehp. 021101025.

[3] A. Seaton, D. Godden, W. MacNee, K. Donaldson, Particulate air pollution and acute health effects, The Lancet 345 (1995) 176-178. doi:10 . 1016/S0140-6736(95)90173-6.

[4] B. Brunekreef, S. Holgate, Air pollution and health, Lancet 360 (2002) 1233-1242. doi:10. 1016/S0140-6736(02)11274-8.

[5] B. Nemery, P. Hoet, A. Nemmar, The Meuse Valley fog of 1930: An air pollution disaster, Lancet 357 (2001) 704-708. doi:10 . 1016/S0140-6736(00) 04135-0.

[6] W. Helfand, J. Lazarus, P. Theerman, Donora, Pennsylvania: An environmental disaster of the 20th century, American Journal of Public Health 91 (2001) 553. doi:10 . 2105/AJ PH. 91.4 .553$.

[7] H. Orru, M. Maasikmets, T. Lai, T. Tamm, M. Kaasik, V. Kimmel, K. Orru, E. Merisalu, B. Forsberg, Health impacts of particulate matter in five major Estonian towns: Main sources of exposure and local differences, Air Quality, Atmosphere and Health 4 (2011) 247-258. doi:10.1007/s11869-010-0075-6.

[8] A. Analitis, K. Katsouyanni, K. Dimakopoulou, E. Samoli, A. Nikoloulopoulos, Y. Petasakis, G. Touloumi, J. Schwartz, H. Anderson, K. Cambra, F. Forastiere, D. Zmirou, J. Vonk, L. Clancy, B. Kriz, J. Bobvos, J. Pekkanen, Short-term effects of ambient particles on cardiovascular and respiratory mortality, Epidemiology 17 (2006) 230-233. doi:10.1097/ 01. ede.0000199439.57655.6b.

[9] A. Zanobetti, M. Franklin, P. Koutrakis, J. Schwartz, Fine particulate air pollution and its components in association with cause-specific emergency admissions, Environmental Health: A Global Access Science Source 8 (2009). doi:10 . 1186/1476-069X-8-58.

[10] F. Dominici, R. Peng, M. Bell, L. Pham, A. McDermott, S. Zeger, J. Samet, Fine particulate air pollution and hospital admission for cardiovascular and respiratory diseases, Journal of the American Medical Association 295 (2006) 1127-1134. doi:10 .1001/jama.295.10.1127.

[11] C. Lin, L. Labzovskii, H. Mak, J. Fung, A. Lau, S. Kenea, M. Bilal, J. Vande Hey, X. Lu, J. Ma, Observation of PM2.5 using a combination of satellite remote sensing and low-cost sensor network in Siberian urban areas with limited reference monitoring, Atmospheric Environment 227 (2020). doi:10 .1016/j . atmosenv . 2020.117410.

[12] K. Donaldson, X. Li, W. MacNee, Ultrafine (nanometre) particle mediated lung injury, Journal of Aerosol Science 29 (1998) 553-560. doi:10 .1016/S0021-8502 (97) 00464-3.

[13] A. Lyapustin, Y. Wang, S. Korkin, D. Huang, MODIS Collection 6 MAIAC algorithm, Atmospheric Measurement Techniques 11 (2018) 5741-5765. doi:10.5194/ 
amt-11-5741-2018.

[14] X. Yap, M. Hashim, A robust calibration approach for PM10 prediction from MODIS aerosol optical depth, Atmospheric Chemistry and Physics 13 (2013) 3517-3526. doi:10 . 5194/acp-13-3517-2013.

[15] I. Kloog, F. Nordio, B. Coull, J. Schwartz, Incorporating local land use regression and satellite aerosol optical depth in a hybrid model of spatiotemporal PM2.5 exposures in the mid-atlantic states, Environmental Science and Technology 46 (2012) 11913-11921. doi:10.1021/es302673e.

[16] P. Gupta, S. Christopher, Particulate matter air quality assessment using integrated surface, satellite, and meteorological products: Multiple regression approach, Journal of Geophysical Research Atmospheres 114 (2009). doi:10 . 1029/2008JD011496.

[17] J. Wang, S. Christopher, Intercomparison between satellite-derived aerosol optical thickness and PM2.5 mass: Implications for air quality studies, Geophysical Research Letters 30 (2003) ASC 4-1 - ASC 4-4. doi:10 .1029/2003GL018174.

[18] R. Hoff, S. Christopher, Remote sensing of particulate pollution from space: Have we reached the promised land?, Journal of the Air and Waste Management Association 59 (2009) 645-675. doi:10.3155/1047-3289.59.6.645.

[19] OMNO2d File Specification, 2013. URL: https://is.gd/Tc0Xoz. 